\title{
More on Intuitionistic Neutrosophic Soft Sets
}

\author{
Said Broumi ${ }^{1, *}$, Florentin Smarandache ${ }^{2}$ \\ ${ }^{1}$ Faculty of Arts and Humanities, Hay El Baraka Ben M'sik Casablanca B.P. 7951, Hassan II University \\ Mohammedia-Casablanca, Morocco \\ ${ }^{2}$ Department of Mathematics, University of New Mexico,705 Gurley Avenue, Gallup, NM 87301, USA \\ *Corresponding Author: broumisaid78@gmail.com
}

Copyright $(2013$ Horizon Research Publishing All rights reserved

\begin{abstract}
Intuitionistic Neutrosophic soft set theory proposed by S.Broumi and F.Samarandache [28], has been regarded as an effective mathematical tool to deal with uncertainties. In this paper new operations on intuitionistic neutrosophic soft sets have been introduced. Some results relating to the properties of these operations have been established. Moreover, we illustrate their interconnections between each other.
\end{abstract}

Keywords Soft Set, Intuitionistic Fuzzy Soft , Intuitionistic Neutrosophic Soft Sets, Necessity and Possibility Operations

\section{Introduction}

The theory of neutrosophic set (NS), which is the generalization of the classical sets, conventional fuzzy set [1], intuitionistic fuzzy set [2] and interval valued fuzzy set [3], was introduced by Samarandache [4]. This concept has been applied in many fields such as Databases $[5,6]$, Medical diagnosis problem [7], Decision making problem [8],Topology [9],control theory [10] and so on. The concept of neutrosophic set handle indeterminate data whereas fuzzy set theory, and intuitionstic fuzzy set theory failed when the relation are indeterminate.

Later on, several researchers have extended the neutrosophic set theory, such as Bhowmik and M.Pal in [11, 12], in their paper, they defined "intuitionistic neutrosophic set".In [13], A.A.Salam, S.A.Alblowi introduced another concept called "Generalized neutrosophic set". In [14], Wang et al. proposed another extension of neutrosophic set which is" single valued neutrosophic". In 1998 a Russian researcher, Molodtsov proposed a new mathematical tool called" Soft set theory" [ 15],for dealing with uncertainty and how soft set theory is free from the parameterization inadequacy syndrome of fuzzy set theory, rough set theory, probability theory.

In recent time, researchers have contributed a lot towards fuzzification of soft set theory which leads to a series of mathematical models such as Fuzzy soft set [17, 18, 19, 20], generalized fuzzy soft set [21,22], possibility fuzzy soft set [23] and so on, therafter, P.K.Maji and his coworker [24] introduced the notion of intuitionistic fuzzy soft set which is based on a combination of the intuitionistic fuzzy setsand soft set models and studied the properties of intuitionistic fuzzy soft set. Later a lot of extentions of intuitionistic fuzzy soft are appeared such as generalized intuitionistic fuzzy soft set [25], Possibility intuitionistic fuzzy soft set [26] and so on. Few studies are focused on neutrosophication of soft set theory. In [25] P.K.Maji, first proposed a new mathematical model called "Neutrosophic Soft Set" and investigate some properties regarding neutrosophic soft union, neutrosophic soft intersection, complement of a neutrosophic soft set ,De Morgan law etc. Furthermore, in 2013, S.Broumi and F. Smarandache [26] combined the intuitionistic neutrosophic and soft set which lead to a new mathematical model called" intutionistic neutrosophic soft set". They studied the notions of intuitionistic neutrosophic soft set union, intuitionistic neutrosophic soft set intersection, complement of intuitionistic neutrosophic soft set and several other properties of intuitionistic neutrosophic soft set along with examples and proofs of certain results. Also ,in [27] S.Broumi presentedthe concept of "Generalized neutrosophic soft set" by combining the generalized neutrosophic sets [13] and soft set models, studied some properties on it, and presented an application of generalized neutrosophic soft set in decision making problem.

In the present work, we have extended the intuitionistic neutrosophic soft sets defining new operations on it. Some properties of these operations have also been studied.

The rest of this paper is organized as follow: section II deals with some definitions related to soft set theory ,neutrosophic set, intuitionistic neutrosophic set, intuitionistic neutrosophic soft set theory. Section III deals with the necessity operation on intuitionistic neutrosophic soft set. Section IV deals with the possibility operation on intuitionistic neutrosophic soft set. Finally, section $\mathrm{V}$ give the conclusion.

\section{Preliminaries}


In this section we represent definitions needful for next section,we denote by $\mathrm{N}(\mathrm{u})$ the set of all intuitionistic neutrosophic set.

\subsection{Soft Sets (see [15]).}

Let $\mathrm{U}$ be a universe set and $\mathrm{E}$ be a set of parameters. Let $\zeta$ ( $\mathrm{U}$ ) denotes the power set of $\mathrm{U}$ and $\mathrm{A} \subset \mathrm{E}$.

\subsubsection{Definition [15]}

A pair ( $\mathrm{P}, \mathrm{A})$ is called a soft set over $\mathrm{U}$, where $\mathrm{F}$ is a mapping given by $\mathrm{P}: \mathrm{A} \rightarrow \zeta(\mathrm{U})$. In other words, a soft set over $\mathrm{U}$ is a parameterized family of subsets of the universe $\mathrm{U}$. For e $\in A, P$ (e ) may be considered as the set of eapproximate elements of the soft set ( P, A ).

\subsection{Intuitionistic Fuzzy Soft Set}

Let $U$ be an initial universe set and $E$ be the set of parameters. Let $\mathrm{IF}^{\mathrm{U}}$ denote the collection of all intuitionistic fuzzy subsets of $\mathrm{U}$. Let . A $\subseteq$ E pair $\left(\begin{array}{ll}P & A\end{array}\right)$ is called an intuitionistic fuzzy soft set over $\mathrm{U}$ where $\mathrm{P}$ is a mapping given by $\mathrm{P}: \mathrm{A} \rightarrow \mathrm{IF}^{\mathrm{U}}$.

\subsubsection{Defintion}

Let $\mathrm{P}: \mathrm{A} \rightarrow \mathrm{IF}^{\mathrm{U}}$ then $\mathrm{F}$ is a function defined as $\mathrm{P}(\varepsilon)=\{\mathrm{x}$, $\left.\boldsymbol{\mu}_{\boldsymbol{P}(\varepsilon)}(\boldsymbol{x}), \boldsymbol{v}_{\boldsymbol{P}(\varepsilon)}(\boldsymbol{x}): \boldsymbol{x} \in \boldsymbol{U}, \varepsilon \in \boldsymbol{E}\right\}$ where $\mu, v$ denote the degree of membership and degree of non-membership respectively and $\pi=1-\mu-\quad v$, denote the hesitancy degree.

\subsection{Neutrosophic Sets (see $[4]$ ).}

Let $\mathrm{U}$ be an universe of discourse then the neutrosophic set $\mathrm{A}$ is an object having the form

$\left.\mathrm{A}=\left\{<\mathrm{x}: \mathrm{T}_{\mathrm{A}(\mathrm{x})}, \mathrm{I}_{\mathrm{A}(\mathrm{x})}, \mathrm{F}_{\mathrm{A}(\mathrm{x})}\right\rangle, \mathrm{x} \in \mathrm{U}\right\}$, where the functions $\mathrm{T}, \mathrm{I}, \mathrm{F}$ : $\mathrm{U} \rightarrow]^{-} 0,1^{+}[$define respectively the degree of membership (or Truth), the degree of indeterminacy, and the degree of non-membership (or Falsehood) of the element $\mathrm{x} \in \mathrm{U}$ to the set A with the condition.

$$
-0 \leq \mathrm{T}_{\mathrm{A}}(\mathrm{x})+\mathrm{I}_{\mathrm{A}}(\mathrm{x})+\mathrm{F}_{\mathrm{A}}(\mathrm{x}) \leq 3^{+} .
$$

From philosophical point of view, the neutrosophic set takes the value from real standard or non-standard subsets of $]^{-} 0,1^{+}[\text {. So instead of }]^{-} 0,1^{+}[$we need to take the interval $[0,1]$ for technical applications, because $]^{-} 0,1^{+}[$will be difficult to apply in the real applications such as in scientific and engineering problems.

\subsection{Single Valued Neutrosophic Set(see [ 14]).}

\subsubsection{Definition (see [14])}

Let $X$ be a space of points (objects) with generic elements in $\mathrm{X}$ denoted by $\mathrm{X}$. An SVNS A in $\mathrm{X}$ is characterized by a truth-membership function $\mathrm{T}_{\mathrm{A}}(\mathrm{x}), \quad$ an indeterminacy-membership function $\mathrm{I}_{\mathrm{A}}(\mathrm{x})$, and $\mathrm{a}$ falsity-membership function $\mathrm{F}_{\mathrm{A}}(\mathrm{x})$ for each point $\mathrm{x}$ in $\mathrm{X}$, $\mathrm{T}_{\mathrm{A}}(\mathrm{x}), \mathrm{I}_{\mathrm{A}}(\mathrm{x}), \mathrm{F}_{\mathrm{A}}(\mathrm{x}) \in[0,1]$.

When $\mathrm{X}$ is continuous, an SVNS A can be written as

$$
\mathrm{A}=\int_{X} \frac{\left\langle T_{A}(x), I_{A}(x), F_{A}(x),>\right.}{x}, x \in X .
$$

When $\mathrm{X}$ is discrete, an SVNS A can be written as

$$
\mathrm{A}=\sum_{1}^{n} \frac{<T_{A}\left(x_{i}\right), I_{A}\left(x_{i}\right), F_{A}\left(x_{i}\right),>}{x_{i}}, x_{i} \in X
$$

\subsubsection{Definition (see $[4,14]$ )}

A neutrosophic set or single valued neutrosophic set (SVNS ) $\mathrm{A}$ is contained in another neutrosophic set $\mathrm{B}$ i.e. $\mathrm{A} \subseteq \mathrm{B}$ if $\forall \mathrm{x}$ $\in U, T_{A}(x) \leq T_{B}(x), I_{A}(x) \geq I_{B}(x), F_{A}(x) \geq F_{B}(x)$.

\subsubsection{Definition (see [2])}

The complement of a neutrosophic set $\mathrm{A}$ is denoted by $\mathrm{A}^{\mathrm{c}}$ and is defined as $\mathrm{T}_{\mathrm{A}(\mathrm{x})}^{\mathrm{c}}=\mathrm{F}_{\mathrm{A}(\mathrm{x})}, \quad \mathrm{I}_{\mathrm{A}(\mathrm{x})}^{\mathrm{c}}=\mathrm{I}_{\mathrm{A}(\mathrm{x})}$ and $\mathrm{F}_{\mathrm{A}^{\mathrm{C}}(\mathrm{x})}^{\mathrm{c}}=\mathrm{T}_{\mathrm{A}(\mathrm{x})}$ for every $\mathrm{x}$ in $\mathrm{X}$.

A complete study of the operations and application of neutrosophic set can be found in [4] .

\subsection{Intuitionistic Neutrosophic Set}

\subsubsection{Definition (see[11])}

An element $\mathrm{x}$ of $\mathrm{U}$ is called significant with respect to neutrsophic set $\mathrm{A}$ of $\mathrm{U}$ if the degree of truth-membership or falsity-membership or indeterminancy-membership value, i.e., $\mathrm{T}_{\mathrm{A}}(\mathrm{x})$ or $\mathrm{F}_{\mathrm{A}}(\mathrm{x})$ or $\mathrm{I}_{\mathrm{A}}(\mathrm{x}), \leq 0.5$. Otherwise, we call it insignificant. Also, for neutrosophic set the truth-membership, indeterminacy-membership and falsity-membership all can not be significant. We define an intuitionistic neutrosophic set by $\mathrm{A}=\left\{<\mathrm{x}: \mathrm{T}_{\mathrm{A}}(\mathrm{x}), \mathrm{I}_{\mathrm{A}}(\mathrm{x})\right.$, $\left.\mathrm{F}_{\mathrm{A}}(\mathrm{x})>, \mathrm{x} \in \mathrm{U}\right\}$, where

$$
\begin{gathered}
\min \left\{\mathrm{T}_{\mathrm{A}}(\mathrm{x}), \mathrm{F}_{\mathrm{A}}(\mathrm{x})\right\} \leq 0.5, \\
\min \left\{\mathrm{T}_{\mathrm{A}}(\mathrm{x}),, \mathrm{I}_{\mathrm{A}}(\mathrm{x})\right\} \leq 0.5, \\
\min \left\{\mathrm{F}_{\mathrm{A}}(\mathrm{x}), \mathrm{I}_{\mathrm{A}}(\mathrm{x})\right\} \leq 0.5, \text { for all } \mathrm{x} \in \mathrm{U},
\end{gathered}
$$

with the condition

$$
0 \leq \mathrm{T}_{\mathrm{A}}(\mathrm{x})+\mathrm{I}_{\mathrm{A}}(\mathrm{x})+\mathrm{F}_{\mathrm{A}}(\mathrm{x}) \leq 2 .
$$

As an illustration, let us consider the following example.

\subsubsection{Example}

Assume that the universe of discourse $\mathrm{U}=\left\{\mathrm{x}_{1}, \mathrm{x}_{2}, \mathrm{x}_{3}\right\}$, where $\mathrm{x}_{1}$ characterizes the capability, $\mathrm{x}_{2}$ characterizes the trustworthiness and $\mathrm{x}_{3}$ indicates the prices of the objects. It may be further assumed that the values of $x_{1}, x_{2}$ and $x_{3}$ are in $[0,1]$ and they are obtained from some questionnaires of some experts. The experts may impose their opinion in three components viz. the degree of goodness, the degree of indeterminacy and that of poorness to explain the characteristics of the objects. Suppose A is an intuitionistic neutrosophic set ( IN S ) of U, such that, 


$$
\mathrm{A}=\left\{<x_{1}, 0.3,0.5,0.4>,<x_{2}, 0.4,0.2,0.6>,<x_{3}, 0.7,0.3,0.5>\right\},
$$

where the degree of goodness of capability is 0.3 , degree of indeterminacy of capability is 0.5 and degree of falsity of capability is 0.4 etc.

\subsection{Intuitionistic Neutrosophic Soft Sets (see [28 ]).}

\subsubsection{Definition}

Let $\mathrm{U}$ be an initial universe set and $\mathrm{A} \subset \mathrm{E}$ be a set of parameters. Let $\mathrm{N}(\mathrm{U})$ denotes the set of all intuitionistic neutrosophic sets of $\mathrm{U}$. The collection $(\mathrm{P}, \mathrm{A})$ is termed to be the soft intuitionistic neutrosophic set over $\mathrm{U}$, where $\mathrm{F}$ is a mapping given by $\mathrm{P}: \mathrm{A} \rightarrow \mathrm{N}(\mathrm{U})$.

\subsubsection{Example}

Let $U$ be the set of blouses under consideration and $\mathrm{E}$ is the set of parameters (or qualities). Each parameter is a intuitionistic neutrosophic word or sentence involving intuitionistic neutrosophic words. Consider $\mathrm{E}=\{$ Bright, Cheap, Costly, very costly, Colorful, Cotton, Polystyrene, long sleeve, expensive $\}$. In this case, to define a intuitionistic neutrosophic soft set means to point out Bright blouses, Cheap blouses, Blouses in Cotton and so on. Suppose that, there are five blouses in the universe $U$ given by, $U=\left\{b_{1}, b_{2}, b_{3}, b_{4}, b_{5}\right\}$ and the set of parameters $A=\left\{e_{1}, e_{2}, e_{3}, e_{4}\right\}$, where each $e_{i}$ is a specific criterion for blouses:

$e_{1}$ stands for 'Bright',

$e_{2}$ stands for 'Cheap',

$e_{3}$ stands for 'Costly',

$e_{4}$ stands for 'Colorful',

Suppose that,

$\mathrm{P}($ Bright $)=\left\{<\mathrm{b}_{1}, 0.5,0.6,0.3>,<\mathrm{b}_{2}, 0.4,0.7,0.2>,<\mathrm{b}_{3}, 0.6,0.2,0.3>,<\mathrm{b}_{4}, 0.7,0.3,0.2>,<\mathrm{b}_{5}, 0.8,0.2,0.3>\right\}$.

$\mathrm{P}($ Cheap $)=\left\{<\mathrm{b}_{1}, 0.6,0.3,0.5>,<\mathrm{b}_{2}, 0.7,0.4,0.3>,<\mathrm{b}_{3}, 0.8,0.1,0.2>,<\mathrm{b}_{4}, 0.7,0.1,0.3>,<\mathrm{b}_{5}, 0.8,0.3,0.4\right\}$.

$\mathrm{P}($ Costly $\left.\left.\left.)=\left\{<\mathrm{b}_{1}, 0.7,0.4,0.3\right\rangle,\left\langle\mathrm{b}_{2}, 0.6,0.1,0.2\right\rangle,\left\langle\mathrm{b}_{3}, 0.7,0.2,0.5\right\rangle,<\mathrm{b}_{4}, 0.5,0.2,0.6\right\rangle,<\mathrm{b}_{5}, 0.7,0.3,0.2\right\rangle\right\}$.

$\mathrm{P}($ Colorful $)=\left\{<\mathrm{b}_{1}, 0.8,0.1,0.4>,<\mathrm{b}_{2}, 0.4,0.2,0.6>,<\mathrm{b}_{3}, 0.3,0.6,0.4>,<\mathrm{b}_{4}, 0.4,0.8,0.5>,<\mathrm{b}_{5}, 0.3,0.5,0.7>\right\}$.

2.6.3.Definition([28]).Containment of two intuitionistic neutrosophic soft sets

For two intuitionistic neutrosophic soft sets ( P, A ) and ( Q, B ) over the common universe U. We say that ( P, A ) is an intuitionistic neutrosophic soft subset of ( Q, B ) if and only if

(i) $\mathrm{A} \subset \mathrm{B}$.

(ii) $\mathrm{P}(\mathrm{e})$ is an intuitionistic neutrosophic subset of $\mathrm{Q}(\mathrm{e})$.

Or $\mathrm{T}_{\mathrm{P}(\mathrm{e})}(\mathrm{x}) \leq \mathrm{T}_{\mathrm{Q}(\mathrm{e})}(\mathrm{m}), \quad \mathrm{I}_{\mathrm{P}(\mathrm{e})}(\mathrm{m}) \geq \mathrm{I}_{\mathrm{Q}(\mathrm{e})}(\mathrm{m}), \mathrm{F}_{\mathrm{P}(\mathrm{e})}(\mathrm{m}) \geq \mathrm{F}_{\mathrm{Q}(\mathrm{e})}(\mathrm{m}), \forall \mathrm{e} \in \mathrm{A}, \mathrm{x} \in \mathrm{U}$.

We denote this relationship by $(\mathrm{P}, \mathrm{A}) \subseteq(\mathrm{Q}, \mathrm{B})$.

( $P, A)$ is said to be intuitionistic neutrosophic soft super set of $(\mathrm{Q}, \mathrm{B})$ if $(\mathrm{Q}, \mathrm{B})$ is an intuitionistic neutrosophic soft subset of ( $\mathrm{P}, \mathrm{A})$. We denote it by $(\mathrm{P}, \mathrm{A}) \supseteq(\mathrm{Q}, \mathrm{B})$.

2.6.4 .Definition [28]. Equality of two intuitionistic neutrosophic soft sets

Two INSSs ( P, A ) and ( Q, B ) over the common universe U are said to be intuitionistic neutrosophic soft equal if ( P, A ) is an intuitionistic neutrosophic soft subset of ( Q, B ) and (Q, B ) is an intuitionistic neutrosophic soft subset of ( P, A ) which can be denoted by $(\mathrm{P}, \mathrm{A})=(\mathrm{Q}, \mathrm{B})$.

2.6.5. Definition [28]. Complement of an intuitionistic neutrosophic soft set

The complement of an intuitionistic neutrosophic soft set $(\mathrm{P}, \mathrm{A})$ is denoted by $(\mathrm{P}, \mathrm{A})^{\mathrm{c}}$ and is defined by $\left.(\mathrm{P}, \mathrm{A})^{\mathrm{c}}=\left(\mathrm{P}^{\mathrm{c}},\right] \mathrm{A}\right)$, where $\left.\mathrm{P}^{\mathrm{c}}:\right] \mathrm{A} \rightarrow \mathrm{N}(\mathrm{U})$ is a mapping given by $\mathrm{P}^{\mathrm{c}}(\alpha)=$ intutionistic neutrosophic soft complement with $\mathrm{T}_{\mathrm{P}(\mathrm{x})}^{\mathrm{c}}=\mathrm{F}_{\mathrm{P}(\mathrm{x})}, \mathrm{I}_{\mathrm{P}(\mathrm{x})}^{\mathrm{c}}=\mathrm{I}_{\mathrm{P}(\mathrm{x})}$ and $\mathrm{F}_{\mathrm{P}(\mathrm{x})}^{\mathrm{c}}=\mathrm{T}_{\mathrm{P}(\mathrm{x}) \text {. }}$

2.6.6. Definition [28] Union of two intuitionistic neutrosophic soft sets

Let $(\mathrm{P}, \mathrm{A})$ and $(\mathrm{Q}, \mathrm{B})$ be two INSSs over the same universe U.Then the union of $(\mathrm{P}, \mathrm{A})$ and $(\mathrm{Q}, \mathrm{B})$ is denoted by ' $(\mathrm{P}$, A) $\cup(Q, B) '$ and is defined by $(P, A) \cup(Q, B)=(K, C)$, where $C=A \cup B$ and the truth-membership, indeterminacy-membership and falsity-membership of $(\mathrm{K}, \mathrm{C})$ are as follows:

$$
T_{K(e)}(\mathrm{m})=\left\{\begin{array}{c}
\mathrm{T}_{\mathrm{P}(\mathrm{e})}(\mathrm{m}), \text { if } e \in \mathrm{A}-\mathrm{B} \\
\mathrm{T}_{\mathrm{Q}(\mathrm{e})}(\mathrm{m}), \text { if } e \in \mathrm{B}-\mathrm{A} \\
\max \left\{T_{P(e)}(\mathrm{m}), T_{Q(e)}(\mathrm{m})\right\}, \text { if } e \in A \cap B
\end{array}\right.
$$




$$
\begin{gathered}
I_{K(e)}(\mathrm{m})=\left\{\begin{array}{c}
I_{P(e)}(\mathrm{m}), \text { if } e \in \mathrm{A}-\mathrm{B} \\
I_{Q(e)}(\mathrm{m}), \text { if } e \in \mathrm{B}-\mathrm{A} \\
\min \left\{I_{P(e)}(\mathrm{m}), I_{Q(e)}(\mathrm{m})\right\}, \text { if } e \in A \cap B
\end{array}\right. \\
F_{K(e)}(\mathrm{m})=\left\{\begin{array}{c}
F_{P(e)}(\mathrm{m}), \text { if } e \in \mathrm{A}-\mathrm{B} \\
F_{Q(e)}(\mathrm{m}), \text { if } e \in \mathrm{B}-\mathrm{A}
\end{array}\right. \\
\min \left\{F_{P(e)}(\mathrm{m}), F_{Q(e)}(\mathrm{m})\right\}, \text { if } e \in A \cap B
\end{gathered}
$$

2.6.7. Definition. Intersection of two intuitionistic neutrosophic soft sets [28]

Let $(\mathrm{P}, \mathrm{A})$ and $(\mathrm{Q}, \mathrm{B})$ be two INSSs over the same universe $\mathrm{U}$ such that $\mathrm{A} \cap \mathrm{B} \neq 0$. Then the intersection of $(\mathrm{P}, \mathrm{A})$ and $(\mathrm{Q}$, $B)$ is denoted by ' $(P, A) \cap(Q, B)$ ' and is defined by $(P, A) \cap(Q, B)=(K, C)$, where $C=A \cap B$ and the truth-membership, indeterminacy membership and falsity-membership of $(\mathrm{K}, \mathrm{C})$ are related to those of $(\mathrm{P}, \mathrm{A})$ and $(\mathrm{Q}, \mathrm{B})$ by:

$$
\begin{aligned}
& T_{K(e)}(\mathrm{m})=\left\{\begin{array}{c}
T_{P(e)}(\mathrm{m}), \text { if } e \in \mathrm{A}-\mathrm{B} \\
T_{Q(e)}(\mathrm{m}), \text { if } e \in \mathrm{B}-\mathrm{A} \\
\min \left\{T_{P(e)}(\mathrm{m}), T_{Q(e)}(\mathrm{m})\right\}, \text { if } e \in A \cap B
\end{array}\right. \\
& I_{K(e)}(\mathrm{m})=\left\{\begin{array}{c}
I_{P(e)}(\mathrm{m}), \text { if } e \in \mathrm{A}-\mathrm{B} \\
I_{Q(e)}(\mathrm{m}), \text { if } e \in \mathrm{B}-\mathrm{A} \\
\min \left\{I_{P(e)}(\mathrm{m}), I_{Q(e)}(\mathrm{m})\right\}, \text { if } e \in A \cap B
\end{array}\right. \\
& F_{K(e)}(\mathrm{m})=\left\{\begin{array}{c}
F_{P(e)}(\mathrm{m}), \text { if } e \in \mathrm{A}-\mathrm{B} \\
F_{Q(e)}(\mathrm{m}), \text { if } e \in \mathrm{B}-\mathrm{A} \\
\max \left\{F_{P(e)}(\mathrm{m}), F_{Q(e)}(\mathrm{m})\right\}, \text { if } e \in A \cap B
\end{array}\right.
\end{aligned}
$$

In this paper we are concerned with intuitionistic neutrosophic sets whose $\mathrm{T}_{\mathrm{A}}, \mathrm{I}_{\mathrm{A}}$ and $\mathrm{F}_{\mathrm{A}}$ values are single points in $[0,1]$ instead of subintervals/subsets in $[0,1]$

\section{The Necessity Operation on Intuitionistic Neutrosophic Soft Set}

In this section,we shall introduce the necessity operation on intuitionistic neutrosophic soft set

\subsection{Remark}

$$
s_{A}=T_{A}+I_{A}+F_{A}, s_{B}=T_{B}+I_{B}+F_{B} \quad \text { if } s_{A}=s_{B} \text { we put } \mathrm{S}=s_{A}=s_{B}
$$

\subsection{Definition}

The necessity operation on an intuitionistic neutrosophic soft set ( P, A ) is denoted by ( P, A ) and is defined as

$$
(\mathrm{P}, \mathrm{A})=\left\{<\mathrm{m}, \mathrm{T}_{P(e)}(m), \mathrm{I}_{P(e)}(m), s_{A}-\mathrm{T}_{P(e)}(m)>\mid \mathrm{m} \in \mathrm{U} \text { and } \mathrm{e} \in \mathrm{A}\right\},
$$

where $s_{A}=\mathrm{T}+\mathrm{I}+\mathrm{F}$.

Here $\mathrm{T}_{\mathrm{P}(\mathrm{e})}(\mathrm{m})$ is the neutrosophic membership degree that object $\mathrm{m}$ hold on parameter $\mathrm{e}, \mathrm{I}_{P(e)}(m)$ represent the indeterminacy function and $\mathrm{P}$ is a mapping $\mathrm{P}: \mathrm{A} \rightarrow \mathrm{N}(\mathrm{U}), \mathrm{N}(\mathrm{U})$ is the set of aintuitionistic neutrosophic sets of $\mathrm{U}$.

\subsection{Example}

Let there are five objects as the universal set where $\mathrm{U}=\left\{\mathrm{m}_{1}, \mathrm{~m}_{2}, \mathrm{~m}_{3}, \mathrm{~m}_{4}, \mathrm{~m}_{5}\right\}$ and the set of parameters as $\mathrm{E}=\{$ beautiful, moderate, wooden, muddy, cheap, costly $\}$ and

Let $\mathrm{A}=\{$ beautiful, moderate, wooden\}. Let the attractiveness of the objects represented by the intuitionistic neutrosophic soft sets $(\mathrm{P}, \mathrm{A})$ is given as

$$
\begin{gathered}
\mathrm{P}(\text { beautiful })=\left\{\mathrm{m}_{1 /(.6,2 ., 4)}, \mathrm{m}_{2 /(.7, .3, .2)}, \mathrm{m}_{3 /(.5, .4, .4)}, \mathrm{m}_{4 /(.6, .4, .3)}, \mathrm{m}_{5 /(.8, .4, .1)}\right\} \\
\mathrm{P}(\text { moderate })=\left\{\mathrm{m}_{1 /(.7, .3, .2)}, \mathrm{m}_{2 /(.8,1, .1)}, \mathrm{m}_{3 /(.7, .5, .2)}, \mathrm{m}_{4 /(.8 .5, .1)}, \mathrm{m}_{5 /(1, .2,0)}\right\} \\
\text { and } \mathrm{P}(\text { wooden })=\left\{\mathrm{m}_{1 /(.8, .5, .1)}, \mathrm{m}_{2 /(.6,4,4)}, \mathrm{m}_{3 /(.6, .5, .2)}, \mathrm{m}_{4 /(.2, .3,4)}, \mathrm{m}_{5 /(.3,2 . .5)}\right\}
\end{gathered}
$$

Then the intuitionistic neutrosophicsoft sets $(\mathrm{P}, \mathrm{A})$ becomes as 


$$
\begin{aligned}
& \mathrm{P}(\text { beautiful })=\left\{\mathrm{m}_{1 /(.6,2, .6)}, \mathrm{m}_{2 /(.7, .3, .5)}, \mathrm{m}_{3 /(.5, .4, .8)}, \mathrm{m}_{4 /(.6, .4, .7)}, \mathrm{m}_{5 /(.8, .4, .5)}\right\} \\
& \mathrm{P}(\text { moderate })=\left\{\mathrm{m}_{1 /(.7, .3, .5)}, \mathrm{m}_{2 /(.8, .1, .2)}, \mathrm{m}_{3 /(.7, .5, .7)}, \mathrm{m}_{4 /(.8, .5, .6)}, \mathrm{m}_{5 /(1, .2, .2}\right\}
\end{aligned}
$$

And

$$
\mathrm{P}(\text { wooden })=\left\{\mathrm{m}_{1 /(.8, .5, .6)}, \mathrm{m}_{2 /(.6, .4,4)}, \mathrm{m}_{3 /(.6, .5, .7)}, \mathrm{m}_{4 /(.2, .3, .7)}, \mathrm{m}_{5 /(.3, .2, .7)}\right\} .
$$

Let $(\mathrm{P}, \mathrm{A})$ and $(\mathrm{Q}, \mathrm{B})$ be two intuitionistic neutrosophic soft sets over a universe $\mathrm{U}$ and $\mathrm{A}, \mathrm{B}$ be two sets of parameters. Then we have the following propositions:

\subsection{Proposition}

$$
\begin{aligned}
& \text { i. } \square[(\mathrm{P}, \mathrm{A}) \mathrm{U}(\mathrm{Q}, \mathrm{B})]=\square(\mathrm{P}, \mathrm{A}) \cup \square(\mathrm{Q}, \mathrm{B}) \text {. } \\
& \text { ii. } \square[(\mathrm{P}, \mathrm{A}) \mathrm{\cap}(\mathrm{Q}, \mathrm{B})]=\square(\mathrm{P}, \mathrm{A}) \cap \square(\mathrm{G}, \mathrm{B}) \text {. } \\
& \text { iii. } \square \square(\mathrm{P}, \mathrm{A})=\square(\mathrm{P}, \mathrm{A}) \text {. } \\
& \text { iv. } \square[(\mathrm{P}, \mathrm{A})]^{\mathrm{n}}=[\square(\mathrm{P}, \mathrm{A})]^{\mathrm{n}}
\end{aligned}
$$

for any finite positive integer $n$.

$$
\begin{aligned}
& \text { v. } \square[(\mathrm{P}, \mathrm{A}) \cup(\mathrm{Q}, \mathrm{B})]^{n}=[\square(\mathrm{P}, \mathrm{A}) \cup \square(\mathrm{Q}, \mathrm{B})]^{n} . \\
& \text { vi. } \square[(\mathrm{P}, \mathrm{A}) \cap(\mathrm{Q}, \mathrm{B})]^{n}=[\square(\mathrm{P}, \mathrm{A}) \cap \square(\mathrm{Q}, \mathrm{B})]^{n} .
\end{aligned}
$$

\section{Proof}

i. $[(P, A) \cup(Q, B)]$

suppose $(\mathrm{P}, \mathrm{A}) \cup(\mathrm{Q}, \mathrm{B})=(\mathrm{H}, \mathrm{C})$, where $\mathrm{C}=\mathrm{A} \cup \mathrm{B}$ and for all $\mathrm{e} \in \mathrm{C}$ and

$s_{A}=T_{P(e)}+I_{P(e)}+F_{P(e)}$ and $s_{B}=T_{Q(e)}+I_{Q(e)}+F_{Q(e)}, s_{A}-\mathrm{T}_{P(e)}(m)=\mathrm{I}_{P(e)}(m)+\mathrm{F}_{P(e)}(m), s_{B}-\mathrm{T}_{Q(e)}(m)=\mathrm{I}_{Q(e)}(m)+$ $\mathrm{F}_{Q(e)}(m)$,

$$
\begin{aligned}
& T_{H(e)}(\mathrm{m})=\left\{\begin{array}{c}
\mathrm{T}_{P(e)}(m), \text { if } e \in \mathrm{A}-\mathrm{B} \\
\mathrm{T}_{Q(e)}(m), \text { if } e \in \mathrm{B}-\mathrm{A} \\
\max \left\{T_{P(e)(m)}, T_{Q(e)(m)}\right\}, \text { if } e \in A \cap B
\end{array}\right. \\
& I_{H(e)}(\mathrm{m})=\left\{\begin{array}{c}
\mathrm{I}_{P(e)}(m), \text { if } e \in \mathrm{A}-\mathrm{B} \\
\mathrm{I}_{Q(e)}(m), \text { if } e \in \mathrm{B}-\mathrm{A} \\
\min \left\{\mathrm{I}_{P(e)}(m), \mathrm{I}_{Q(e)}(m)\right\}, \text { if } e \in A \cap B
\end{array}\right. \\
& F_{H(e)}(\mathrm{m})=\left\{\begin{array}{c}
\mathrm{F}_{P(e)}(m), \text { if } e \in \mathrm{A}-\mathrm{B} \\
\mathrm{F}_{Q(e)}(m), \text { if } e \in \mathrm{B}-\mathrm{A} \\
\min \left\{\mathrm{F}_{P(e)}(m), \mathrm{F}_{Q(e)}(m)\right\}, \text { if } e \in A \cap B
\end{array}\right.
\end{aligned}
$$

Since $[(P, A) \cup(Q, B)]=(H, C)$ and $m \in U$, by definition 3.2 we Have

$$
\begin{aligned}
& T_{H(e)}(\mathrm{m})=\left\{\begin{array}{c}
T_{P(e)}(\mathrm{m}), \text { if } e \in \mathrm{A}-\mathrm{B} \\
T_{Q(e)}(\mathrm{m}), \text { if } e \in \mathrm{B}-\mathrm{A} \\
\max \left\{T_{P(e)}(\mathrm{m}), T_{Q(e)}(\mathrm{m})\right\}, \text { if } e \in A \cap B
\end{array}\right. \\
& I_{H(e)}(\mathrm{m})=\left\{\begin{array}{c}
I_{P(e)}(\mathrm{m}), \text { if } e \in \mathrm{A}-\mathrm{B} \\
I_{Q(e)}(\mathrm{m}), \text { if } e \in \mathrm{B}-\mathrm{A} \\
\min \left\{I_{P(e)}(\mathrm{m}), I_{Q(e)}(\mathrm{m})\right\}, \text { if } e \in A \cap B
\end{array}\right. \\
& F_{H(e)}(\mathrm{m})=\left\{\begin{array}{c}
s_{A}-T_{P(e)}(\mathrm{m}), \text { if } e \in \mathrm{A}-\mathrm{B}, \\
s_{B}-T_{Q(e)}(\mathrm{m}), \text { if } e \in \mathrm{B}-\mathrm{A} \\
S-\max \left\{T_{P(e)}(\mathrm{m}), T_{Q(e)}(\mathrm{m})\right\}, \text { if } e \in A \cap B
\end{array}\right.
\end{aligned}
$$

For all e $\in \mathrm{C}=\mathrm{A} \cup \mathrm{B}$ and $\mathrm{m} \in \mathrm{U}$. Assume that $\square(\mathrm{P}, \mathrm{A})=\left\{<\mathrm{m}, T_{P(e)}(m), I_{P(e)}(m), s_{A}-T_{P(e)}(m)>, \mathrm{m} \in \mathrm{U}\right\}$ and $\square$ $(\mathrm{Q}, \mathrm{A})=\left\{<m, T_{O(e)}(\mathrm{m}) \quad, I_{O(e)}(\mathrm{m}) \quad, S_{B}-T_{O(e)}(\mathrm{m}) \quad, \mathrm{m} \in \mathrm{U}\right\}$.Suppose that $(\mathrm{P}, \mathrm{A}) \cup \quad(\mathrm{Q}, \mathrm{B})=(\mathrm{O}, \mathrm{C})$, where $\mathrm{C}=\mathrm{A} \cup$ $\mathrm{B}$,and for all $\mathrm{e} \in \mathrm{C}$ and $\mathrm{m} \in \mathrm{U}$. 


$$
\begin{aligned}
& T_{O(e)}(\mathrm{m})=\left\{\begin{array}{c}
T_{P(e)}(\mathrm{m}), \text { if } e \in \mathrm{A}-\mathrm{B} \\
T_{Q(e)}(\mathrm{m}), \text { if } e \in \mathrm{B}-\mathrm{A} \\
\max \left\{T_{P(e)}(\mathrm{m}), T_{Q(e)}(\mathrm{m})\right\}, \text { if } e \in A \cap B
\end{array}\right. \\
& I_{O(e)}(\mathrm{m})=\left\{\begin{array}{c}
I_{P(e)}(\mathrm{m}), \text { if } e \in \mathrm{A}-\mathrm{B} \\
I_{Q(e)}(\mathrm{m}), \text { if } e \in \mathrm{B}-\mathrm{A} \\
\min \left\{I_{P(e)}(\mathrm{m}), I_{Q(e)}(\mathrm{m})\right\}, \text { if } e \in A \cap B
\end{array}\right. \\
& F_{O(e)}(\mathrm{m})=\left\{\begin{array}{c}
s_{A}-T_{P(e)}(\mathrm{m}), \text { if } e \in \mathrm{A}-\mathrm{B} \\
s_{B}-T_{Q(e)}(\mathrm{m}), \text { if } e \in \mathrm{B}-\mathrm{A} \\
\min \left\{s_{A}-T_{P(e)}(\mathrm{m}), s_{A}-T_{Q(e)}(\mathrm{m})\right\}, \text { if } e \in A \cap B
\end{array}\right. \\
& =\left\{\begin{array}{c}
s_{A}-T_{P(e)}(\mathrm{m}), \text { if } e \in \mathrm{A}-\mathrm{B} \\
s_{B}-T_{Q(e)}(\mathrm{m}), \text { if } e \in \mathrm{B}-\mathrm{A} \\
S-\max \left\{T_{P(e)}(\mathrm{m}), T_{Q(e)}(\mathrm{m})\right\}, \\
\text { if } e \in A \cap B \text { with } S=s_{A}=s_{B}
\end{array}\right.
\end{aligned}
$$

Consequently, $(\mathrm{H}, \mathrm{C})$ and $(\mathrm{O}, \mathrm{C})$ are the same intuitionistic neutrosophic soft sets.Thus,

$$
((\mathrm{P}, \mathrm{A}) \cup(\mathrm{Q}, \mathrm{B}))=\square(\mathrm{P}, \mathrm{A}) \cup \square(\mathrm{Q}, \mathrm{B}) \text {. }
$$

Hence the result is proved.

(ii) and (iii) are proved analogously.

iii. Let

$$
(\mathrm{P}, \mathrm{A})=\left\{<\mathrm{m}, \mathrm{T}_{\mathrm{P}(\mathrm{e})}(\mathrm{m}), \mathrm{I}_{\mathrm{P}(\mathrm{e})}(\mathrm{m}), \mathrm{F}_{\mathrm{P}(\mathrm{e})}(\mathrm{m}),>\mid \mathrm{m} \in \mathrm{U} \text { and } \mathrm{e} \in \mathrm{A}\right\} .
$$

Then

$$
(\mathrm{P}, \mathrm{A})=\left\{<\mathrm{m}, \mathrm{T}_{\mathrm{P}(\mathrm{e})}(\mathrm{m}), \mathrm{I}_{\mathrm{P}(\mathrm{e})}(\mathrm{m}), \mathrm{s}_{\mathrm{A}}-\mathrm{T}_{\mathrm{P}(\mathrm{e})}(\mathrm{m})>\mid \mathrm{m} \in \mathrm{U} \text { and } \mathrm{e} \in \mathrm{A}\right\}
$$

So

$$
\square \square(\mathrm{P}, \mathrm{A})=\left\{<\mathrm{m}, \mathrm{T}_{\mathrm{P}(\mathrm{e})}(\mathrm{m}), \mathrm{I}_{P(e)}(\mathrm{m}), s_{A^{-}} T_{P(e)}(\mathrm{m})>\mid \mathrm{m} \in \mathrm{U} \text { and } \mathrm{e} \in \mathrm{A}\right\} .
$$

Hence the result follows.

iv. Let the intuitionistic neutrosophic soft set

$$
(\mathrm{P}, \mathrm{A})=\left\{<\mathrm{m}, T_{P(e)}(\mathrm{m}), \mathrm{I}_{P(e)}(\mathrm{m}), \quad \mathrm{F}_{P(e)}(\mathrm{m})>\mid \mathrm{m} \in \mathrm{U} \text { and } \mathrm{e} \in \mathrm{A}\right\} .
$$

Then for any finite positive integer $\mathrm{n}$

$$
(\mathrm{P}, \mathrm{A})^{n}=\left\{<\mathrm{m},\left[\mathrm{T}_{\mathrm{P}(\mathrm{e})}(\mathrm{m})\right]^{n},\left[\mathrm{I}_{\mathrm{P}(\mathrm{e})}(\mathrm{m})\right]^{n}, s_{A}-\left[s_{A}-\mathrm{F}_{\mathrm{P}(\mathrm{e})}(\mathrm{m})\right]^{\mathrm{n}}>\mid \mathrm{m} \in \mathrm{U} \text { and } \mathrm{e} \in \mathrm{A}\right\}
$$

So,

$\square(\mathrm{P}, \mathrm{A})^{n}=\left\{<\mathrm{m},\left[\mathrm{T}_{\mathrm{P}(\mathrm{e})}(\mathrm{m})\right]^{n},\left[\mathrm{I}_{\mathrm{P}(\mathrm{e})}(\mathrm{m})\right]^{n}, s_{A^{-}}\left[\mathrm{T}_{\mathrm{P}(\mathrm{e})}(\mathrm{m})\right]^{n}>\mid \mathrm{m} \in \mathrm{U}\right.$ and $\left.\mathrm{e} \in \mathrm{A}\right\}$.

Again, $[\square(\mathrm{P}, \mathrm{A})]^{n}=\left\{<\mathrm{m},\left[\mathrm{T}_{\mathrm{P}(\mathrm{e})}(\mathrm{m})\right]^{n},\left[\mathrm{I}_{\mathrm{P}(\mathrm{e})}(\mathrm{m})\right]^{n}, s_{A^{-}}\left[\mathrm{T}_{\mathrm{P}(\mathrm{e})}(\mathrm{m})\right]^{n}>\mid \mathrm{m} \in \mathrm{U}\right.$ and $\left.\mathrm{e} \in \mathrm{A}\right\}$ as

$$
\square(\mathrm{P}, \mathrm{A})=\left\{<\mathrm{m}, T_{P(e)}(\mathrm{m}), \mathrm{I}_{P(e)}(\mathrm{m}), s_{A}-T_{P(e)}(\mathrm{m})>\mid \mathrm{m} \in \mathrm{U} \text { and } \mathrm{e} \in \mathrm{A}\right\} \text {. }
$$

Hence the result.

v. As $(P, A)^{n} \cup(Q, B)^{n}=[(P, A) \cup(Q, B)]^{n}$

$\begin{aligned} \square[(\mathrm{P}, \mathrm{A}) \cup(\mathrm{Q}, \mathrm{B})]^{n} & =[\boxminus[(\mathrm{P}, \mathrm{A}) \cup(\mathrm{Q}, \mathrm{B})]]^{n} \quad \text { by the proposition 3.4.iv } \\ =[\square(\mathrm{P}, \mathrm{A}) \cup \square(\mathrm{Q}, \mathrm{B})]^{n} & \text { by the proposition 3.4.i }\end{aligned}$

vi. As $(P, A)^{n} \cap(Q, B)^{n}=[(P, A) \cap(Q, B)]^{n}$

So, $\square[(\mathrm{P}, \mathrm{A}) \cap(\mathrm{Q}, \mathrm{B})]^{n}=[\square[(\mathrm{P}, \mathrm{A}) \cap(\mathrm{Q}, \mathrm{B})]]^{n}$ by the proposition3.4.iv

The result is proved.

$$
=[\square(\mathrm{P}, \mathrm{A}) \cap \square(\mathrm{Q}, \mathrm{B})]^{n} \text { by the proposition 3.4.ii }
$$

The concept of necessity operation on intuitionistic neutrosophic soft set can also be applied to measure the necessity operation on intuitionistic fuzzy soft set (IFSS), proposed by P.K .Maji [30], where the indeterminacy degree $\mathrm{I}_{\mathrm{P}(\mathrm{e})}(\mathrm{m})$ 
should be replaced by $\mathrm{I}_{\mathrm{P}(\mathrm{e})}(\mathrm{m})=1-\mathrm{T}_{\mathrm{P}(\mathrm{e})}(\mathrm{m})-\mathrm{F}_{\mathrm{P}(\mathrm{e})}(\mathrm{m})$ in case of IFSS. In this case, we conclude that the necessity operation on intuitionistic neutrosophic soft set is a generalization of the necessity operation on intuitionistic fuzzy soft set

\section{The Possibility Operation on Intuitionistic Neutrosophic Soft Sets}

In this section, we shall define another operation, the possibility operation on intuitionistic neutrosophic soft sets.

Let $\mathrm{U}$ be a universal set. $\mathrm{E}$ be a set of parameters and $\mathrm{A}$ be a subset of E. Let the intuitionistic neutrosophic soft set. $(\mathrm{P}, \mathrm{A})=\left\{<\mathrm{m}, \mathrm{T}_{P(e)}(m), \mathrm{I}_{P(e)}(m), \mathrm{F}_{P(e)}(m)>\mid \mathrm{m} \in \mathrm{U}\right.$ and $\left.\mathrm{e} \in \mathrm{A}\right\}$, where $\mathrm{T}_{P(e)}(m), \mathrm{I}_{P(e)}(m), \mathrm{F}_{P(e)}(m)$ be the membership, indeterminacyand non-membership functions respectively.

\subsection{Definition}

Let $U$ be the universal set and $\mathrm{E}$ be the set of parameters. The possibility operation on the intuitionistic neutrosophic soft set $(\mathrm{P}, \mathrm{A})$ is denoted by $\diamond(\mathrm{P}, \mathrm{A})$ and is defined as

$$
\diamond(\mathrm{P}, \mathrm{A})=\left\{<\mathrm{m}, s_{A^{-}} \mathrm{F}_{\mathrm{P}(\mathrm{e})}(\mathrm{m}), \quad \mathrm{I}_{\mathrm{P}(\mathrm{e})}(\mathrm{m}), \quad \mathrm{F}_{\mathrm{P}(\mathrm{e})}(\mathrm{m})>\mid \mathrm{m} \in \mathrm{U} \text { and } \mathrm{e} \in \mathrm{A}\right\},
$$

where

$$
s_{A}=\mathrm{T}_{P(e)}(m)+\mathrm{I}_{P(e)}(m)+\mathrm{F}_{P(e)}(m) \text { and } 0^{-} \leq s_{A} \leq 3^{+}
$$

\subsection{Example}

Let there are five objects as the universal set where $U=\left\{\mathrm{m}_{1}, \mathrm{~m}_{2}, \mathrm{~m}_{3}, \mathrm{~m}_{4}, \mathrm{~m}_{5}\right\}$. Also let the set of parameters as $\mathrm{E}=$ \{ beautiful, costly, cheap, moderate, wooden, muddy $\}$ and $\mathrm{A}=\{$ costly, cheap, moderate $\}$. The cost of the objects represented by the intuitionistic neutrosophic soft sets

$(\mathrm{P}, \mathrm{A})$ is given as

$$
\begin{aligned}
& \mathrm{P}(\text { costly })=\left\{\mathrm{m}_{1 /(.7, .1, .2)}, \mathrm{m}_{2 /(.8, .3,0)}, \mathrm{m}_{3 /(.8, .2, .1)}, \mathrm{m}_{4 /(.9,4.4)}, \mathrm{m}_{5 /(.6, .2, .2)}\right\} \\
& \mathrm{P}(\text { cheap })=\left\{\mathrm{m}_{1 /(.5, .3, .2)}, \mathrm{m}_{2 /(.7, .5, .1)}, \mathrm{m}_{3 /(.4,3, .2)}, \mathrm{m}_{4 /(.8, .5, .1)}, \mathrm{m}_{5 /(.4,4, .2)}\right\}
\end{aligned}
$$

and

$$
\mathrm{P}(\text { moderate })=\left\{\mathrm{m}_{1 /(.8, .4, .2)}, \mathrm{m}_{2 /(.6, .1,3)}, \mathrm{m}_{3 /(.5,5, .1)}, \mathrm{m}_{4 /(.9, .4,0)}, \mathrm{m}_{5 /(.7,3,3,1)}\right\} .
$$

Then the neutrosophic soft set $\diamond(P, A)$ is as

$$
\begin{aligned}
& \mathrm{P}(\text { costly })=\left\{\mathrm{m}_{1 /(.8,1, .2)}, \mathrm{m}_{2 /(1.1,3,0)}, \mathrm{m}_{3 /(1, .2, .1)}, \mathrm{m}_{4 /(1.3,4,4,0)}, \mathrm{m}_{5 /(.8,2 ., 2)}\right\}, \\
& \mathrm{P}(\text { cheap })=\left\{\mathrm{m}_{1 /(.8,3, .2)}, \mathrm{m}_{2 /(1.2, .5,1)}, \mathrm{m}_{3 /(.7,3, .2)}, \mathrm{m}_{4 /(1.3, .5,1)}, \mathrm{m}_{5 /(.8,4, .2}\right\}
\end{aligned}
$$

and

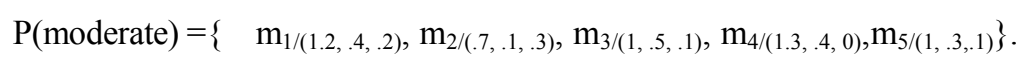

The concept of possibilty operation on intuitionistic neutrosophic soft set can also be applied to measure the necessity operation on intuitionistic fuzzy soft set (IFSS), proposed by P.K .Maji [30], where the indeterminacy degree $\mathrm{I}_{\mathrm{P}(\mathrm{e})}(\mathrm{m})$

should be replaced by $\mathrm{I}_{\mathrm{P}(\mathrm{e})}(\mathrm{m})=1-\mathrm{T}_{\mathrm{P}(\mathrm{e})}(\mathrm{m})-\mathrm{F}_{\mathrm{P}(\mathrm{e})}(\mathrm{m})$ in case of IFSS. In this case, we conclude that the possibility operation on intuitionistic neutrosophic soft set is a generalization of the possibility operation on intuitionistic fuzzy soft set.

Let ( P, A ) and ( Q, B ) be two intuitionistic neutrosophic soft sets over the same universe U and A, B be two sets of parameters. Then we have the propositions

\subsection{Proposition}

$$
\begin{aligned}
& \text { i. } \diamond[(\mathrm{P}, \mathrm{A}) \cup(\mathrm{Q}, \mathrm{B})]=\diamond(\mathrm{P}, \mathrm{A}) \cup \diamond(\mathrm{Q}, \mathrm{B}) . \\
& \text { ii. } \diamond[(\mathrm{P}, \mathrm{A}) \cap(\mathrm{Q}, \mathrm{B})]=\diamond(\mathrm{P}, \mathrm{A}) \cap \diamond(\mathrm{Q}, \mathrm{B}) \\
& \text { iii. } \diamond(\mathrm{P}, \mathrm{A})=\diamond(\mathrm{P}, \mathrm{A}) . \\
& \text { iv. } \diamond[(\mathrm{P}, \mathrm{A})]^{n}=[\diamond(\mathrm{P}, \mathrm{A})]^{n}
\end{aligned}
$$

for any finite positive integer $n$. 


$$
\begin{aligned}
& \text { v. } \diamond[(\mathrm{P}, \mathrm{A}) \cup(\mathrm{Q}, \mathrm{B})]^{n}=[\diamond(\mathrm{P}, \mathrm{A}) \cup \diamond(\mathrm{Q}, \mathrm{B})]^{n} . \\
& \text { vi. } \diamond[(\mathrm{P}, \mathrm{A}) \cap(\mathrm{Q}, \mathrm{B})]^{n}=[\diamond(\mathrm{P}, \mathrm{A}) \cap \diamond(\mathrm{Q}, \mathrm{B})]^{n}
\end{aligned}
$$

\section{Proof}

i. $\diamond[(\mathrm{P}, \mathrm{A}) \cup(\mathrm{Q}, \mathrm{B})]$

suppose $(\mathrm{P}, \mathrm{A}) \cup(\mathrm{Q}, \mathrm{B})=(\mathrm{H}, \mathrm{C})$, where $\mathrm{C}=\mathrm{A} \cup \mathrm{B}$ and for all $\mathrm{e} \in \mathrm{C}$ and

$$
\begin{aligned}
& s_{A}=\mathrm{T}_{P(e)}(m)+\mathrm{I}_{P(e)}(m)+\mathrm{F}_{P(e)}(m) \text { and } s_{B}=\mathrm{T}_{Q(e)}(m)+\mathrm{I}_{Q(e)}(m)+\mathrm{F}_{Q(e)}(m) \\
& s_{A}-F_{P(e)}(\mathrm{m})=I_{P(e)}(\mathrm{m})+T_{P(e)}(\mathrm{m}), \\
& s_{B}-F_{Q(e)}(\mathrm{m})=I_{P(e)}(\mathrm{m})+T_{Q(e)}(\mathrm{m}) \\
& T_{H(e)}(\mathrm{m})=\left\{\begin{array}{c}
T_{P(e)}(\mathrm{m}), \text { if } e \in \mathrm{A}-\mathrm{B} \\
T_{Q(e)}(\mathrm{m}), \text { if } e \in \mathrm{B}-\mathrm{A} \\
\max \left\{T_{P(e)}(\mathrm{m}), T_{Q(e)}(\mathrm{m})\right\}, \text { if } e \in A \cap B
\end{array}\right. \\
& I_{H(e)}(\mathrm{m})=\left\{\begin{array}{c}
I_{P(e)}(\mathrm{m}), \text { if } e \in \mathrm{A}-\mathrm{B} \\
I_{Q(e)}(\mathrm{m}), \text { if } e \in \mathrm{B}-\mathrm{A} \\
\min \left\{I_{P(e)}(\mathrm{m}), I_{Q(e)}(\mathrm{m})\right\}, \text { if } e \in A \cap B
\end{array}\right. \\
& F_{H(e)}(\mathrm{m})=\left\{\begin{array}{c}
F_{P(e)}(\mathrm{m}), \text { if } e \in \mathrm{A}-\mathrm{B} \\
F_{Q(e)}(\mathrm{m}), \text { if } e \in \mathrm{B}-\mathrm{A} \\
\min \left\{F_{P(e)(m)}, F_{Q(e)(m)}, \text { if } e \in A \cap B\right.
\end{array}\right.
\end{aligned}
$$

Since $\diamond[(\mathrm{P}, \mathrm{A}) \cup(\mathrm{Q}, \mathrm{B})]=\diamond(\mathrm{H}, \mathrm{C})$ and $\mathrm{m} \in \mathrm{U}$, by definition 4.1 we Have

$$
\begin{gathered}
T_{H(e)}(\mathrm{m})=\left\{\begin{array}{c}
s_{A}-F_{P(e)}(\mathrm{m}), \text { if } e \in \mathrm{A}-\mathrm{B} \\
s_{B}-F_{Q(e)}(\mathrm{m}), \text { if } e \in \mathrm{B}-\mathrm{A} \\
S-\min \left\{F_{P(e)}(\mathrm{m}), F_{Q(e)}(\mathrm{m})\right\}, \\
\text { if } e \in A \cap B, \text { with } S=s_{A}=s_{B}
\end{array}\right. \\
I_{H(e)}(\mathrm{m})=\left\{\begin{array}{c}
I_{P(e)}(\mathrm{m}), \text { if } e \in \mathrm{A}-\mathrm{B} \\
I_{Q(e)}(\mathrm{m}), \text { if } e \in \mathrm{B}-\mathrm{A}
\end{array}\right. \\
F_{H(e)}(\mathrm{m})=\left\{\begin{array}{c}
\min \left\{I_{P(e)}(\mathrm{m}), I_{Q(e)}(\mathrm{m})\right\}, \text { if } e \in A \cap B \\
F_{P(e)}(\mathrm{m}), \text { if } e \in \mathrm{A}-\mathrm{B} \\
F_{Q(e)}(\mathrm{m}), \text { if } e \in \mathrm{B}-\mathrm{A}
\end{array}\right. \\
\min \left\{F_{P(e)}(\mathrm{m}), F_{Q(e)}(\mathrm{m})\right\}, \text { if } e \in A \cap B
\end{gathered}
$$

For all $\mathrm{e} \in \mathrm{C}=\mathrm{A} \cup \mathrm{B}$ and $\mathrm{m} \in \mathrm{U}$. Assume that

$$
\diamond(\mathrm{P}, \mathrm{A})=\left\{<\mathrm{m}, s_{A}-F_{P(e)}(\mathrm{m}), I_{P(e)}(\mathrm{m}), F_{P(e)}(\mathrm{m})>, \mathrm{m} \in \mathrm{U}\right\}
$$

and

$$
\diamond(\mathrm{Q}, \mathrm{B})=\left\{<m, s_{B}-F_{Q(e)}(\mathrm{m}), I_{Q(e)}(\mathrm{m}), F_{Q(e)}(\mathrm{m})>, \mathrm{m} \in \mathrm{U}\right\} .
$$

Suppose that

$$
\diamond(\mathrm{P}, \mathrm{A}) \cup \diamond(\mathrm{Q}, \mathrm{B})=(\mathrm{O}, \mathrm{C}),
$$

where $\mathrm{C}=\mathrm{A} \cup \mathrm{B}$, and for all $\mathrm{e} \in \mathrm{C}$ and $\mathrm{m} \in \mathrm{U}$.

$$
\begin{aligned}
& T_{O(e)}(\mathrm{m})=\left\{\begin{array}{c}
s_{A}-F_{P(e)}(\mathrm{m}),, \text { if } e \in \mathrm{A}-\mathrm{B} \\
s_{B}-F_{Q(e)}(\mathrm{m}), \text { if } e \in \mathrm{B}-\mathrm{A} \\
\max \left\{s_{A}-F_{P(e)}(\mathrm{m}), s_{B}-F_{Q(e)}(\mathrm{m})\right\}, \text { if } e \in A \cap B
\end{array}\right. \\
& =\left\{\begin{array}{c}
s_{A}-F_{P(e)}(\mathrm{m}), \text { if } e \in \mathrm{A}-\mathrm{B} \\
S_{B}-F_{Q(e)}(\mathrm{m}), \text { if } e \in \mathrm{B}-\mathrm{A} \\
S-\min \left\{F_{P(e)}(\mathrm{m}), F_{Q(e)}(\mathrm{m})\right\}, \text { if } e \in A \cap B, \\
\text { with } S=s_{A}=s_{B}
\end{array}\right.
\end{aligned}
$$




$$
\begin{gathered}
I_{O(e)}(\mathrm{m})=\left\{\begin{array}{c}
I_{P(e)}(\mathrm{m}), \text { if } e \in \mathrm{A}-\mathrm{B} \\
I_{Q(e)}(\mathrm{m}), \text { if } e \in \mathrm{B}-\mathrm{A} \\
\min \left\{I_{P(e)}(\mathrm{m}), I_{Q(e)}(\mathrm{m})\right\}, \text { if } e \in A \cap B
\end{array}\right. \\
F_{O(e)}(\mathrm{m})=\left\{\begin{array}{c}
F_{P(e)}(\mathrm{m}), \text { if } e \in \mathrm{A}-\mathrm{B} \\
F_{Q(e)}(\mathrm{m}), \text { if } e \in \mathrm{B}-\mathrm{A} \\
\min \left\{F_{P(e)}(\mathrm{m}), F_{Q(e)}(\mathrm{m})\right\}, \text { if } e \in A \cap B
\end{array}\right.
\end{gathered}
$$

Consequently, $\diamond(\mathrm{H}, \mathrm{C})$ and $(\mathrm{O}, \mathrm{C})$ are the same intuitionistic neutrosophic soft sets. Thus,

$$
\diamond((\mathrm{P}, \mathrm{A}) \cup \quad(\mathrm{Q}, \mathrm{B}))=\diamond(\mathrm{P}, \mathrm{A}) \cup \diamond(\mathrm{Q}, \mathrm{B}) .
$$

Hence the result is proved.

(ii) and (iii) are proved analogously.

$$
\text { iii. } \left.\left.\diamond(\mathrm{P}, \mathrm{A})=\left\{<\mathrm{m}, s_{A^{-}}-\mathrm{F}_{P(e)}(m), \mathrm{I}_{P(e)}(m)\right], \mathrm{F}_{P(e)}(m)\right]>\mid \mathrm{m} \in \mathrm{U} \text { and } \mathrm{e} \in \mathrm{A}\right\} \text {. }
$$

So

$$
\left.\diamond \diamond(\mathrm{P}, \mathrm{A})=\left\{<\mathrm{m}, s_{A}-\mathrm{F}_{P(e)}(m), \mathrm{I}_{P(e)}(m), \mathrm{F}_{P(e)}(m)\right]>\mid \mathrm{m} \in \mathrm{U} \text { and } \mathrm{e} \in \mathrm{A}\right\} .
$$

Hence the result.

iv. For any positive finite integer $n$,

$$
\left.(\mathrm{P}, \mathrm{A})^{n}=\left\{<\mathrm{m},\left[\mathrm{T}_{P(e)}(m)\right]^{n}, \quad\left[\mathrm{I}_{P(e)}(m)\right]^{n}, s_{A}-\left[s_{A}-\mathrm{F}_{P(e)}(m)\right]\right]^{n}>\mid \mathrm{m} \in \mathrm{U}\right\} \forall \mathrm{e} \in \mathrm{A},
$$

So,

$$
\begin{gathered}
\diamond(\mathrm{P}, \mathrm{A})^{n}=\left\{<\mathrm{m}, s_{A^{-}}\left[s_{A^{-}}\left[s_{A}-\mathrm{F}_{P(e)}(m)\right]^{n}\right],\left[\mathrm{I}_{P(e)}(m)\right]^{n}, s_{A^{-}}-\left[s_{A}-\mathrm{F}_{P(e)}(m)\right]^{n}>\mid \mathrm{m} \in \mathrm{U}\right\} \\
=\left\{<\mathrm{m},\left[s_{A}-\mathrm{F}_{P(e)}(m)\right]^{n},\left[\mathrm{I}_{P(e)}(m)\right]^{n}, s_{A}-\left[s_{A}-\mathrm{F}_{P(e)}(m)\right]^{n}>\mid \mathrm{m} \in \mathrm{U}\right\} \forall \mathrm{e} \in \mathrm{A} .
\end{gathered}
$$

Again

$$
[\diamond(\mathrm{P}, \mathrm{A})]^{n}=\left\{<\mathrm{m},\left[s_{A}-\mathrm{F}_{P(e)}(m)\right]^{n},\left[\mathrm{I}_{P(e)}(m)\right]^{n}, s_{A}-\left[s_{A}-\mathrm{F}_{P(e)}(m)\right]^{n}>\mid \mathrm{m} \in \mathrm{U}\right\} \forall \mathrm{e} \in \mathrm{A} .
$$

Hence the result follows.

v. As $[(\mathrm{P}, \mathrm{A}) \cup(\mathrm{Q}, \mathrm{B})]^{n}=(\mathrm{P}, \mathrm{A})^{n} \cup(\mathrm{Q}, \mathrm{B})^{n}$,

$\diamond[(\mathrm{P}, \mathrm{A}) \cup(\mathrm{Q}, \mathrm{B})]^{n}==\diamond(\mathrm{P}, \mathrm{A})^{n} \cup \diamond(\mathrm{Q}, \mathrm{B})^{n}$.

the result is proved

vi.As $[(\mathrm{P}, \mathrm{A}) \cap(\mathrm{Q}, \mathrm{B})]^{n}=(\mathrm{P}, \mathrm{A})^{n} \cap(\mathrm{Q}, \mathrm{B})^{n}$,

$\diamond[(\mathrm{P}, \mathrm{A}) \cap(\mathrm{Q}, \mathrm{B})]^{n}=\diamond(\mathrm{P}, \mathrm{A})^{n} \cap \diamond(\mathrm{Q}, \mathrm{B})^{n}$.

Hence the result follows.

For any intuitionistic neutrosophic soft set $(\mathrm{P}, \mathrm{A})$ we have the following propositions.

\subsection{Proposition}

$$
\begin{aligned}
& \text { i. } \diamond \square(\mathrm{P}, \mathrm{A})=\square(\mathrm{P}, \mathrm{A}) \\
& \text { ii. } \square \diamond(\mathrm{P}, \mathrm{A})=\diamond(\mathrm{P}, \mathrm{A})
\end{aligned}
$$

\section{Proof}

i.Let $(\mathrm{P}, \mathrm{A})$ be a intuitionistic neutrosophic soft set over the universe $\mathrm{U}$.

Then $(\mathrm{P}, \mathrm{A})=\left\{<\mathrm{m}, \mathrm{T}_{P(e)}(m), \mathrm{I}_{P(e)}(m), \mathrm{F}_{P(e)}(m)>\mid \mathrm{m} \in \mathrm{U}\right\}$ where $\mathrm{e} \in \mathrm{A}$.

So, $\square(\mathrm{P}, \mathrm{A})=\left\{<\mathrm{m}, \mathrm{T}_{P(e)}(m), \mathrm{I}_{P(e)}(m), s_{A^{-}} \mathrm{T}_{P(e)}(m)>\mid \mathrm{m} \in \mathrm{U}\right\}$, and $\diamond(\mathrm{P}, \mathrm{A})=\left\{<\mathrm{m}, s_{A}-\mathrm{F}_{P(e)}(m), \mathrm{I}_{P(e)}(m), \mathrm{F}_{P(e)}(m)>\mid \mathrm{m} \in \mathrm{U}\right\}$.

So $\diamond \square(\mathrm{P}, \mathrm{A})=\left\{<\mathrm{m}, s_{A^{-}}\left(s_{A^{-}}-\mathrm{T}_{P(e)}(m)\right), \mathrm{I}_{P(e)}(m), s_{A^{-}}-\mathrm{T}_{P(e)}(m)>\mid \mathrm{m} \in \mathrm{U}\right\}$.

$=\left\{<\mathrm{m}, \mathrm{T}_{P(e)}(m), \mathrm{I}_{P(e)}(m), s_{A^{-}} \mathrm{T}_{P(e)}(m)>\mid \mathrm{m} \in \mathrm{U}\right\}$.

$=\square(\mathrm{P}, \mathrm{A})$

ii.The proof is similar to the proof of the proposition 3.4.i. 
Let ( P, A ) and ( Q, B ) be two intuitionistic neutrosophic soft sets over the common universe U, then we have the following propositions:

\subsection{Proposition}

$$
\begin{aligned}
& \text { i. } \square[(\mathrm{P}, \mathrm{A}) \wedge(\mathrm{Q}, \mathrm{B})]=\square(\mathrm{P}, \mathrm{A}) \wedge \square(\mathrm{Q}, \mathrm{B}) . \\
& \text { ii. } \square[(\mathrm{P}, \mathrm{A}) \vee(\mathrm{Q}, \mathrm{B})]=\square(\mathrm{P}, \mathrm{A}) \vee \square(\mathrm{Q}, \mathrm{B}) . \\
& \text { iii. } \diamond[(\mathrm{P}, \mathrm{A}) \wedge(\mathrm{Q}, \mathrm{B})]=\diamond(\mathrm{P}, \mathrm{A}) \wedge \diamond(\mathrm{Q}, \mathrm{B}) . \\
& \text { iv. } \diamond[(\mathrm{P}, \mathrm{A}) \vee(\mathrm{Q}, \mathrm{B})]=\diamond(\mathrm{P}, \mathrm{A}) \vee \diamond(\mathrm{Q}, \mathrm{B}) .
\end{aligned}
$$

\section{Proof}

i. Let $(\mathrm{H}, \mathrm{A} \times \mathrm{B})=(\mathrm{P}, \mathrm{A}) \wedge(\mathrm{Q}, \mathrm{B})$.

Hence,

$$
(\mathrm{H}, \mathrm{A} \times \mathrm{B})=\left\{<\mathrm{m}, \mathrm{T}_{H(\alpha, \beta)}(\mathrm{m}), \mathrm{I}_{H(\alpha, \beta)}(\mathrm{m}), \mathrm{F}_{H(\alpha, \beta)}(\mathrm{m})(\mathrm{m})>\mid \mathrm{m} \in \mathrm{U}\right\},
$$

where

$$
\mathrm{T}_{H(\alpha, \beta)}(\mathrm{m})=\min \left\{\mathrm{T}_{P(\alpha)}(\mathrm{m}), \mathrm{T}_{Q(\beta)}(\mathrm{m})\right\}, \mathrm{F}_{H(\alpha, \beta)}(\mathrm{m})=\max \left\{\mathrm{F}_{P(\alpha)}(\mathrm{m}), \mathrm{F}_{Q(\beta)}(\mathrm{m})\right\}
$$

and

$$
\mathrm{I}_{H(\alpha, \beta)}(\mathrm{m})=\max \left\{\mathrm{I}_{P(\alpha)}(\mathrm{m}), \mathrm{I}_{Q(\beta)}(\mathrm{m})\right\} .
$$

So,

$\square(\mathrm{H}, \mathrm{A} \times \mathrm{B})=\left\{<\mathrm{m}, \mathrm{T}_{H(\alpha, \beta)}(\mathrm{m}), \mathrm{I}_{H(\alpha, \beta)}(\mathrm{m}), \mathrm{S}-\mathrm{T}_{H(\alpha, \beta)}(\mathrm{m})>\mid \mathrm{m} \in \mathrm{U}\right\},(\alpha, \beta) \in \mathrm{A} \times \mathrm{B}$

$=\left\{<\mathrm{m}, \min \left(\mathrm{T}_{P(\alpha)}(\mathrm{m}), \mathrm{T}_{Q(\beta)}(\mathrm{m})\right), \max \left(\mathrm{I}_{P(\alpha)}(\mathrm{m}), \mathrm{I}_{Q(\beta)}(\mathrm{m})\right), \mathrm{S}-\min \left(\mathrm{T}_{P(\alpha)}(\mathrm{m}), \mathrm{T}_{Q(\beta)}(\mathrm{m})\right)>\mid \mathrm{m} \in \mathrm{U}\right\}$

$=\left\{<\mathrm{m}, \min \left(\mathrm{T}_{P(\alpha)}(\mathrm{m}), \mathrm{T}_{Q(\beta)}(\mathrm{m})\right), \max \left(\mathrm{I}_{P(\alpha)}(\mathrm{m}), \mathrm{I}_{Q(\beta)}(\mathrm{m})\right), \max \left(\mathrm{S}-\mathrm{T}_{P(\alpha)}(\mathrm{m}), \mathrm{S}-\mathrm{T}_{Q(\beta)}(\mathrm{m})\right)>\mid \mathrm{m} \in \mathrm{U}\right\}$

$=\left\{<\mathrm{m}, \mathrm{T}_{P(\alpha)}(\mathrm{m}), \mathrm{I}_{P(\alpha)}(\mathrm{m}), \mathrm{S}-\mathrm{T}_{P(\alpha)}(\mathrm{m})>\mid \mathrm{m} \in \mathrm{U}\right\}$ AND $\left\{<\mathrm{m}, \mathrm{T}_{Q(\beta)}(\mathrm{m}), \mathrm{I}_{Q(\beta)}(\mathrm{m}), \mathrm{S}-\mathrm{T}_{Q(\beta)}(\mathrm{m})>\mid \mathrm{m} \in \mathrm{U}\right\}$

$=\square(\mathrm{P}, \mathrm{A}) \wedge \square(\mathrm{Q}, \mathrm{B})$.

Hence the result is proved

ii. Let $(\mathrm{L}, \mathrm{A} \times \mathrm{B})=(\mathrm{P}, \mathrm{A}) \vee(\mathrm{Q}, \mathrm{B})$.

Hence,

$$
(\mathrm{L}, \mathrm{A} \times \mathrm{B})=\left\{<\mathrm{m}, \mathrm{T}_{L(\alpha, \beta)}(\mathrm{m}), \mathrm{I}_{L(\alpha, \beta)}(\mathrm{m}), \mathrm{F}_{L(\alpha, \beta)}(\mathrm{m})>\mid \mathrm{m} \in \mathrm{U}\right\}
$$

where

$$
\mathrm{T}_{L(\alpha, \beta)}(\mathrm{m})=\max \left\{\mathrm{T}_{P(\alpha)}(\mathrm{m}), \mathrm{T}_{Q(\beta)}(\mathrm{m})\right\}, \mathrm{I}_{L(\alpha, \beta)}(\mathrm{m})=\min \left\{\mathrm{I}_{\mathrm{P}(\alpha)}(\mathrm{m}), \mathrm{I}_{Q(\beta)}(\mathrm{m})\right\}
$$

And $\quad \mathrm{F}_{L(\alpha, \beta)}(\mathrm{m})=\min \left\{\mathrm{F}_{P(\beta)}(\mathrm{m}), \mathrm{F}_{Q(\beta)}(\mathrm{m})\right\}$.

So,

$\square(\mathrm{L}, \mathrm{A} \times \mathrm{B})=\left\{<\mathrm{m}, \mathrm{T}_{L(\alpha, \beta)}(\mathrm{m}), \mathrm{I}_{L(\alpha, \beta)}(\mathrm{m}), \mathrm{S}-\mathrm{T}_{L(\alpha, \beta)}(\mathrm{m})>\mid \mathrm{m} \in \mathrm{U}\right\}$, for $(\alpha, \beta) \in \mathrm{A} \times \mathrm{B}$

$=\left\{<\mathrm{m}, \max \left(\mathrm{T}_{P(\alpha)}(\mathrm{m}), \mathrm{T}_{Q(\beta)}(\mathrm{m})\right), \min \left(\mathrm{I}_{\mathrm{P}(\alpha)}(\mathrm{m}), \mathrm{I}_{Q(\beta)}(\mathrm{m})\right), \mathrm{S}-\max \left(\mathrm{T}_{P(\alpha)}(\mathrm{m}), \mathrm{T}_{Q(\beta)}(\mathrm{m})\right)>\mid \mathrm{m} \in \mathrm{U}\right\}$

$=\left\{<\mathrm{m}, \max \left(\mathrm{T}_{P(\alpha)}(\mathrm{m}), \mathrm{T}_{Q(\beta)}(\mathrm{m})\right), \min \left(\mathrm{I}_{\mathrm{P}(\alpha)}(\mathrm{m}), \mathrm{I}_{Q(\beta)}(\mathrm{m})\right), \min \left(\mathrm{S}-\mathrm{T}_{P(\alpha)}(\mathrm{m}), \mathrm{S}-\mathrm{T}_{Q(\beta)}(\mathrm{m})\right)>\mid \mathrm{m} \in \mathrm{U}\right\}$

$=\left\{<\mathrm{m}, \mathrm{T}_{P(\alpha)}(\mathrm{m}), \mathrm{I}_{\mathrm{P}(\alpha)}(\mathrm{m}), \mathrm{S}-\mathrm{T}_{P(\alpha)}(\mathrm{m})>\mid \mathrm{m} \in \mathrm{U}\right\}$ OR $\left\{<\mathrm{m}, \mathrm{T}_{Q(\beta)}(\mathrm{m}), \mathrm{I}_{Q(\beta)}(\mathrm{m}), \mathrm{S}-\mathrm{T}_{Q(\beta)}(\mathrm{m})>\mid \mathrm{m} \in \mathrm{U}\right\}$

$=\square(\mathrm{P}, \mathrm{A}) \vee \square(\mathrm{Q}, \mathrm{B})$.

Hence the result is proved

iii. Let $(\mathrm{H}, \mathrm{A} \times \mathrm{B})=(\mathrm{P}, \mathrm{A}) \wedge(\mathrm{Q}, \mathrm{B})$.

Hence,

$$
(\mathrm{H}, \mathrm{A} \times \mathrm{B})=\left\{<\mathrm{m}, \mathrm{T}_{H(\alpha, \beta)}(\mathrm{m}), \mathrm{I}_{H(\alpha, \beta)}(\mathrm{m}), \mathrm{F}_{H(\alpha, \beta)}(\mathrm{m})>\mid \mathrm{m} \in \mathrm{U}\right\},
$$

where

$$
\mathrm{T}_{H(\alpha, \beta)}(\mathrm{m})=\min \left\{\mathrm{T}_{P(\alpha)}(\mathrm{m}), \mathrm{T}_{Q(\beta)}(\mathrm{m})\right\}, \mathrm{I}_{H(\alpha, \beta)}(\mathrm{m})=\max \left\{\mathrm{I}_{P(\alpha)}(\mathrm{m}), \mathrm{I}_{Q(\beta)}(\mathrm{m})\right\}
$$


and

$$
\mathrm{F}_{H(\alpha, \beta)}(\mathrm{m})=\max \left\{\mathrm{F}_{P(\alpha)}(\mathrm{m}), \mathrm{F}_{Q(\beta)}(\mathrm{m})\right\} .
$$

So,

$$
\begin{aligned}
& \diamond(\mathrm{H}, \mathrm{A} \times \mathrm{B})=\left\{<\mathrm{m}, \mathrm{S}-\mathrm{F}_{H(\alpha, \beta)}(\mathrm{m}), \mathrm{I}_{H(\alpha, \beta)}(\mathrm{m}), \mathrm{F}_{H(\alpha, \beta)}(\mathrm{m})>\mid \mathrm{m} \in \mathrm{U}\right\}, \text { for }(\alpha, \beta) \in \mathrm{A} \times \mathrm{B} \\
= & \left\{<\mathrm{m}, \mathrm{S}-\max \left(\mathrm{F}_{P(\alpha)}(\mathrm{m}), \mathrm{F}_{Q(\beta)}(\mathrm{m})\right), \max \left(\mathrm{I}_{P(\alpha)}(\mathrm{m}), \mathrm{I}_{Q(\beta)}(\mathrm{m})\right), \max \left(\mathrm{F}_{P(\alpha)}(\mathrm{m}), \mathrm{F}_{Q(\beta)}(\mathrm{m})\right)>\mid \mathrm{m} \in \mathrm{U}\right\} \\
= & \left\{<\mathrm{m}, \min \left(\mathrm{S}-\mathrm{F}_{P(\alpha)}(\mathrm{m}), \mathrm{S}-\mathrm{F}_{Q(\beta)}(\mathrm{m})\right), \max \left(\mathrm{I}_{P(\alpha)}(\mathrm{m}), \mathrm{I}_{Q(\beta)}(\mathrm{m})\right), \max \left(\mathrm{F}_{P(\alpha)}(\mathrm{m}), \mathrm{F}_{Q(\beta)}(\mathrm{m})\right)>\mid \mathrm{m} \in \mathrm{U}\right\} \\
= & \left\{<\mathrm{m}, \mathrm{S}-\mathrm{F}_{P(\alpha)}(\mathrm{m}), \mathrm{I}_{P(\alpha)}(\mathrm{m}), \mathrm{F}_{P(\alpha)}(\mathrm{m})>\mid \mathrm{m} \in \mathrm{U}\right\} \operatorname{AND}\left\{<\mathrm{m}, \mathrm{S}-\mathrm{F}_{Q(\beta)}(\mathrm{m}), \mathrm{I}_{Q(\beta)}(\mathrm{m}), \mathrm{F}_{Q(\beta)}(\mathrm{m})>\mid \mathrm{m} \in \mathrm{U}\right\}
\end{aligned}
$$

$=\diamond(\mathrm{P}, \mathrm{A}) \wedge \diamond(\mathrm{Q}, \mathrm{B})$. Hence the result is proved

iv. The proof is similar to the proof of the proposition 3.5.iii.

\section{Conclusion}

In the present work, We have continued to study the properties of intuitionistic neutrosophic soft set. New operations such as necessity and possibility on the intuitionistic neutrosophic soft set are introduced. Some properties of these operations and their interconnection between each other are also presented and discussed. We conclude that necessity and possibility operations on the intuitionistic neutrosophic soft set are generalization of necessity and possibility operations on the intuitionistic fuzzy soft set. The new operations can be applied also on neutrosophic soft set [27] and generalized neutrosophic soft set [29]. We hope that the findings, in this paper will help researcher enhance the study on the intuitionistic neutrosophic soft set theory.

\section{Acknowledgements}

The authors would like to thank the anonymous reviewer for their careful reading of this article and for their helpful comments.

\section{REFERENCES}

[1] L.A.Zadeh. Fuzzy sets. Information and Control.(1965), 8: pp.338-353.

[2] K.Atanassov. Intuitionistic fuzzy sets.Fuzzy Sets and Systems.(1986), 20,pp.87-96.

[3] Turksen, "Interval valued fuzzy sets based on normal forms".Fuzzy Sets and Systems, 20,(1968),pp.191-210.

[4] F.Smarandache, "A Unifying Field in Logics. Neutrosophy: Neutrosophic Probability, Set and Logic". Rehoboth: American Research Press,(1999).

[5] M.Arora, R.Biswas,U.S.Pandy, "Neutrosophic Relational Database Decomposition", International Journal of Advanced Computer Science and Applications, Vol. 2, No. 8, (2011), pp.121-125.

[6] M. Arora and R. Biswas," Deployment of Neutrosophic technology to retrieve answers for queries posed in natural language", in 3rdInternational Conference on Computer
Science and Information Technology ICCSIT, IEEE catalog Number CFP1057E-art,Vol.3, ISBN: 978-1-4244-5540-9,(2010), pp. 435-439.

[7] Ansari, Biswas, Aggarwal,"Proposal forApplicability of Neutrosophic Set Theory in Medical AI", International Journal of Computer Applications (0975 - 8887), Vo 27No.5, (2011), pp:5-11

[8] A. Kharal, "A Neutrosophic Multicriteria Decision Making Method",New Mathematics \& Natural Computation, to appear in Nov 2013.

[9] F.G Lupiáñez, "On neutrosophic topology", Kybernetes, Vol. 37 Iss: 6,(2008), pp.797 800 ,Doi:10.1108/03684920810876990.

[10] S. Aggarwal, R. Biswas,A.Q.Ansari,'Neutrosophic Modeling and Control",978-1-4244-9034-/10/\$26.00@2010 IEEE, pp.718-723.

[11] M. Bhowmik and M. Pal ," Intuitionistic Neutrosophic Set", ISSN 1746-7659, England, UK, Journal of Information and Computing Science,Vol. 4, No. 2, (2009), pp. 142-152.

[12] M. Bhowmik and M. Pal ," Intuitionistic Neutrosophic Set Relations and Some of Its Properties ,ISSN 1746-7659, England, UK, Journal of Information and Computing Science, Vol. 5, No. 3, (2010), pp. 183-192.

[13] A. A. Salama, S.A.Alblowi, "Generalized Neutrosophic Set and Generalized Neutrosophic Topological Spaces" ,Computer Science and Engineering, p-ISSN: 2163-1484 e-ISSN: 2163-1492 DOI: 10.5923/j.computer.20120207.01,(2012), 2(7), pp. 129-132

[14] Wang, H., Smarandache, F., Zhang, Y. Q., Sunderraman, R,"Singlevalued neutrosophic",sets.Multispace and Multistructure, 4,(2010), pp. 410-413.

[15] D. A. Molodtsov, "Soft Set Theory - First Result", Computers and Mathematics with Applications, Vol. 37, (1999), pp. 19-31.

[16] P. K. Maji, R. Biswas and A.R. Roy, "Fuzzy Soft Sets", Journal of Fuzzy Mathematics, Vol 9 , no.3, (2001), pp. 589-602.

[17] B. Ahmad, and A. Kharal, On Fuzzy Soft Sets, Hindawi Publishing Corporation, Advances in Fuzzy Systems, volume Article ID 586507, (2009), 6pages doi: $10.1155 / 2009 / 586507$.

[18] P. K. Maji, A. R. Roy and R. Biswas, "Fuzzy soft 
sets" Journal of Fuzzy Mathematics. 9 (3),(2001), pp.589-602.

[19] T. J. Neog and D. K. Sut, "On Fuzzy Soft Complement and Related Properties", Accepted for publication in International, Journal of Energy, Information and communications (IJEIC).

[20] M. Borah, T. J. Neog and D. K. Sut,” A study on some operations of fuzzy soft sets", International Journal of Modern Engineering Research (IJMER), Vol.2, Issue. 2,(2012), pp. 157-168.

[21] H. L. Yang, "Notes On Generalized Fuzzy Soft Sets", Journal of Mathematical Research and Exposition, Vol 31, No. 3, (2011), pp.567-570

[22] P. Majumdar, S. K. Samanta, "Generalized Fuzzy Soft Sets", Computers and Mathematics with Applications,59,(2010), pp.1425-1432.

[23] S. Alkhazaleh, A. R. Salleh, and N. Hassan,'Possibility Fuzzy Soft Set",Advances in Decision Sciences,Vol2011, Article ID 479756,18 pages,doi:10.1155/2011/479756.

[24] P. K. Maji, R. Biswas, A. R. Roy, "Intuitionistic fuzzy soft sets", The journal of fuzzy mathematics 9(3),( 2001$)$, pp.677-692.
[25] K.V .Babitha.and J. J. Sunil,"'Generalized Intuitionistic Fuzzy Soft Sets and Its Applications ",Gen. Math. Notes, ISSN 2219-7184; Copyright (C) ICSRS Publication, (2011), Vol. 7, No. 2, (2011), pp.1-14.

[26] M.Bashir, A.R. Salleh, and S. Alkhazaleh," Possibility Intuitionistic Fuzzy Soft Set", Advances in Decision Sciences Volume 2012 (2012), Article ID 404325, 24 pages, doi: $10.1155 / 2012 / 404325$.

[27] P. K. Maji," Neutrosophic Soft Set”, Annals of Fuzzy Mathematics and Informatics,Vol 5, No. 1,ISSN: 2093-9310(online) ,ISSN: 2287-623(print).

[28] S.Broumi and F. Smarandache, "Intuitionistic Neutrosophic Soft Set", Journal of Information and Computing Science, England, UK ,ISSN 1746-7659,Vol. 8, No. 2, (2013), pp.130-140.

[29] S.Broumi, "Generalized Neutrosophic Soft Set", International Journal of Computer Science, Engineering and Information Technology (IJCSEIT), ISSN: 2231-3605, E-ISSN : 2231-3117, Vol.3, No.2, (2013), pp.17-30.

[30] P. K. Maji," More on Intuitionistic Fuzzy Soft Set”,Springer -Verlag Berlin Heidelberg, H.Sakai et al.( Eds):RSFDGrC 2009.LNAI 5908, pp231-240. 